\title{
Intracranial hypertension and papilloedema in chronic inflammatory demyelinating polyneuropathy
}

\author{
Aldo Fantin, Richard M Feist, Chittaranjan V Reddy
}

Chronic inflammatory demyelinating polyneuropathy (CIDP) is a diagnosis based upon clinical signs and symptoms, electrodiagnostic studies, lumbar puncture, laboratory tests, and, occasionally, nerve biopsy. CIDP is characterised by a slowly progressive or relapsing course. ${ }^{12}$ To our knowledge no case of CIDP meeting current diagnostic criteria ${ }^{1}$ has been associated with intracranial hypertension. We describe such a case with the additional, unusual, complication of vitreous haemorrhage due to papilloedema.

\section{Case report}

A 19-year-old, non-obese white man was followed for 2 years for idiopathic CIDP characterised by recurrent proximal and distal weakness, distal numbness, areflexia, and decreased pin prick and vibration sensation of the feet. Electrodiagnostic studies supporting the diagnosis of CIDP included marked non-uniform slowing of nerve conduction velocities and prolonged distal median and peroneal nerve latencies. Sural nerve biopsy showed loss of myelinated fibres and onion bulb formation. Cerebrospinal fluid (CSF) protein was $745 \mathrm{mg}$ / $100 \mathrm{ml}$ with no cells. Systemic evaluation revealed no concurrent disease.

Following 5 months of treatment with prednisone $60 \mathrm{mg}$ every other day and azathioprine $50 \mathrm{mg}$ three times per day, with no dose changes in either medication, the patient developed bitemporal headaches. Visual acuity was $20 / 20$ in the right eye and $20 / 15$ in the left eye with a $0.6 \mathrm{log}$ unit relative afferent pupillary defect of the right eye. Fundus examination showed bilateral disc oedema and Goldmann visual field evaluation revealed bilateral enlargement of the blind spot with a caecocentral scotoma in the right eye. Opening pressure on lumbar puncture was $520 \mathrm{~mm} \mathrm{CSF}$ with $913 \mathrm{mg}$ / $100 \mathrm{ml}$ protein and white blood cell count of $3 \times 10^{6} / 1$. CSF electrophoresis revealed two restricted bands in the $\gamma$ region. Owing to markedly increased CSF protein, evidence for increased CNS immunoglobulin synthesis was inconclusive.

Following the diagnosis of intracranial hypertension acetazolamide $1 \mathrm{~g}$ per day was begun. An increase in dosage to $500 \mathrm{mg}$ four times a day was not tolerated. After 6 weeks of acetazolamide treatment the patient noted onset of a shadow near fixation in the right eye. Visual acuity at this time was 20/20 in each eye with a relative afferent defect of $1.2 \mathrm{log}$ units in the right eye. Fundus examination revealed papilloedema greater in the right eye than the left, with dilated disc vessels and a small vitreous haemorrhage overlying the right disc and inferior retina. A computed tomogram of the brain revealed no intracranial haemorrhage or other abnormality.

Owing to increasing relative afferent pupillary defect during maximum tolerated medical therapy, a right optic nerve sheath decompression was performed through a lateral orbitotomy approach. Papilloedema decreased and visual fields improved in both eyes with a reduction of the afferent pupillary defect to 0.6 log units. The patient did not require acetazolamide postoperatively.

\section{Comment}

Papilloedema and intracranial hypertension are uncommon but well recognised complications of the acute inflammatory demyelinating polyneuropathy entity, the Guillain-Barré syndrome. Morley and Reynolds, in a review of 27 GuillainBarré cases, suggested an increased incidence of a relapsing polyneuritis course in these patients. ${ }^{3}$ It is unclear whether the concurrent findings of intracranial hypertension and CIDP in our patient represent a chance or a meaningful association. The elevated CSF protein concentration characteristic of Guillain-Barré syndrome has been felt to increase CSF outflow resistance, but Ropper and Marmarou, could attribute no more than $25 \%$ of the intracranial pressure rise to measured outflow resistance. They proposed increased venous pressure at points of CSF outflow as an alternative cause of intracranial hypertension in Guillain-Barré syndrome. ${ }^{4}$

Regardless of the aetiology of intracranial hypertension, optic nerve sheath fenestration in our patient, as in patients with idiopathic intracranial hypertension, resulted in improvement of papilloedema and prevention of further optic nerve damage.

1 Cornblath DR, Asbury AK, Albers JW, Feasby TE, Hahn AF McLeod JG, et al. Research criteria for diagnosis of chronic inflammatory demyelinating polyneuropathy (CIDP). Neurology 1991; 41: 617-8.

2 Asbury AK. Diseases of the peripheral nervous system. In: Wilson JD, Braunwald E, Isselbacher KJ, Petersdorf RG Martin JB, Fauci AS, et al, eds. Harrison's principles of internal medicine. 12th ed. New York: McGraw-Hill, 1991: 2096-107. medicine. 12th ed. New York: McGraw-Hill, 1991: 2096-107.
Morley JB, Reynolds EH. Papilloedema and the LandryGuillain-Barré syndrome. Case reports and review. Brain 1966; 89: 205-22.

4 Ropper AH, Marmarou A. Mechanism of pseudotumor in Guillain-Barré syndrome. Arch Neurol 1984; 41: 259-61.

5 Corbett JJ, Nerad JA, Tse DT, Anderson RL. Results of optic nerve sheath fenestration for pseudotumor cerebri. The lateral orbitotomy approach. Arch Ophthalmol 1988; 106: 1391-7. 